Anne-Claire E. Beernink Sophie H. N. Swinkels

Jan K. Buitelaar

\section{Problem behavior in a community sample of 14- and 19-month-old children}

\author{
Common versus uncommon behaviors, structure, and \\ stability
}

Accepted: 27 November 2006

Published online: 6 April 2007
A.C.E. Beernink $(\square)$

S.H.N. Swinkels, $\mathrm{PhD}$

J.K. Buitelaar, MD, PhD

Dept. of Psychiatry (966)

University Medical Center St. Radboud

P.O. Box 9101

6500 HB Nijmegen, The Netherlands

E-Mail: a.c.beernink@psy.umcn.nl

S.H.N. Swinkels, PhD

J.K. Buitelaar, $\mathrm{MD}, \mathrm{PhD}$

Academic Center for Child and Adolescent

Psychiatry

Nijmegen, The Netherlands
Abstract Few studies have examined the presence, structure, and stability of behavior problems in a community sample of $14-$ and 19-month-old infants. A questionnaire with items on emotional, attentional, and impulsive behavior and social communication was completed by the parents of 6,491 infants aged 14 months and 1,803 infants aged 19 months. Particularly externalizing behavior problems were reported to present sometimes or often for $50 \%$ of more of the sample and could be considered as common. In contrast, social communication problems were reported to be present in less than $10 \%$ of the sample. Overall, boys showed more problem behaviors than girls. Principal component analysis at the
14 months data revealed seven factors, which could all be replicated in the 19 months data. Pearson correlations between scores at 14 months and 19 months were highest for oppositional and attention factors (0.68 and 0.63 ) and lowest for the inhibiton factor (0.38). More than $50 \%$ of those scoring in the top $10 \%$ for total problem score at 14 months were in the top $10 \%$ at 19 months. These results will facilitate the recognition of psychopathology at very early age and the study of its development over time.

Key words infant development - problem behavior

\section{Introduction}

Psychopathological research has only recently started to focus on the expression of problematic development at a very young age, i.e., younger than 18 months, and few data are available on the expression of problem behavior in somewhat older children between 1- and 3-year-old [5, 9, 23]. Indeed, the lack of normative data for normal and deviant development in children younger than 18 months may lead to inadequate early recognition of serious behavior problems $[8,33,34]$.

The differentiation of normal behavior from problem behavior is particularly challenging in young children [19]. Many symptoms of psychiatric disorders in childhood and adolescence are considered to be relatively normal in preschool-age children. For example, during the preschool years, aggressive, hyperactive, and non-compliance behaviors and separation problems are relatively common and can be viewed as relatively normal within a developmental perspective [6]. Still, these behaviors can be quite stressing for parents and are generally referred to as problem behaviors. Children younger than 18 months are learning to control themselves, to become attached to people and objects, and to explore, and are only beginning to form stable behavior patterns. Earlier studies reported that problem behavior affected between $7.3 \%$ and $24 \%$ of 2 - and 3 -year-old children [5, $12,14,18,20,22,24,26,27,31,32]$, but there are few 
data for children younger than this age. One developmental screening study reported that about $10 \%$ of infants had emotional and behavioral problems in the first year of life [15], and another study reported that about $6 \%$ of the 1 -year-old children had high scores on the Difficult Child domain of the Parenting Stress Index [5].

An important reason to study behavior at a young age is that it may predict problem behavior at a later age. For example, indices of temperament at 3 years were found to predict the presence and the type of psychiatric disorder in young adulthood [10], and behavior problems at 2 years, such as aggression, non-compliance, and difficult temperament, were valuable predictors of lasting problems at a later stage of development [17]. Approximately $50 \%$ of the 2and 3-year-old children with externalizing psychiatric disorders continued to have these problems later in life $[6,21]$. Such problems appear to be stable from an age of 18 months onward [23], but to our knowledge stability has not been evaluated in younger children.

More knowledge on the expression and stability of problem behaviors before the age of 18 months would be advantageous, especially for doctors and nurses working in well baby clinics. In the Netherlands, infants visit well baby clinics according to a fixed scheme. At 14 months there is a relatively extensive check up. Since this is a moment for vaccination the attendance rate for this check up is high. Therefore, more knowledge on problem behaviors at especially 14 -month-old was desirable. The current study was designed to investigate behaviors at this young age and had the following aims.

The first aim was to examine the occurrence of problem behaviors or lack of competences at younger age that are considered to be psychopathological in later childhood. A second aim was to examine whether the constructs of problem behaviors and competences usually found in older children are already present at 14 and 19 months of age. A third aim was to examine the short-term stability of parent-reported problem behavior and lack of competences between age 14 and 19 months. To achieve these aims, we used a questionnaire with 55 items on mainly externalizing and social communication behaviors.

\section{Method}

\section{Sampling}

The sample was a total population birth cohort of children born between August 2000 and August 2001 $(N=12,297)$ in the province of Utrecht in the Netherlands. The province has a population of about 1.117.997 and includes rural and highly urbanized areas. Parents of 14-month-old children received a request from the provincial inoculation center to complete our questionnaire concerning infant problem behavior. This request was accompanied by an information brochure that explained the purpose of this study (at time $t_{1}$ ). Parents of 6,491 infants (i.e., $53 \%$ of the 12,297 infants eligible) returned the questionnaire and consented to participate. About equal numbers of boys and girls participated. Unfortunately, we were not allowed access to information on non-responders, and so we investigated potential selection bias by comparing the data of responders to demographic data for the province of Utrecht [25]. Responders lived somewhat less often in urban areas (responders $46.6 \%$, province of Utrecht $48.1 \%$ ) and had a higher educational level, which was defined as parents with at least a high school or college degree (responders sample: mothers $43.4 \%$; fathers $44.2 \%$; province of Utrecht: mothers $38.9 \%$; and fathers $36.0 \%)$. Chi-square test for differences confirmed significant differences with respect to urbanization grade $\left(\chi^{2}=86.437, \mathrm{df} 4, P<0.000\right)$ and educational level of the mother $\left(\chi^{2}=328.56\right.$, df 2 , $P<0.000)$ and of the father $\left(\chi^{2}=313.18\right.$, df 2 , $P<0.000)$. Further, our sample contained significantly fewer children (responder sample: 5.3\%, province of Utrecht: 17.94\%) of non-Dutch descent $\left(\chi^{2}=695.785\right.$, df $\left.5, P<0.000\right)$.

To parents of children born in June, July, and August $2001(N=4,051)$ who had also received the questionnaire at 14 months and had returned the questionnaire the first time, the questionnaire was sent again (at time $t_{2}$ ) when the children were 19 months of age. This time 1,803 subjects (44\%, 919 boys, 889 girls) participated. There were no significant differences in demographic characteristics between the 19-month-old group and the 14-month-old group. For further analyses of the 14- and 19-month-old data, we used the 14-month-old data $(N=6,491)$, and the 19 -month-old sample $(N=1,803)$, respectively. When both samples were compared we used the combined sample $(N=1,803)$.

\section{Description of participants}

Approximately $88 \%$ of the parents were Dutch, $1.3 \%$ were Turkish, $1.8 \%$ were Moroccan, $1.3 \%$ were from the Caribbean (Surinam or the Dutch Antilles), 0.4\% were from other Western countries, and $0.5 \%$ were of non-Western origin. Questionnaires were completed by mothers $(80.5 \%)$, fathers $(10.7 \%)$, and by both $(0.6 \%)$. Mean child age was 14.80 months $(S D=1.84)$. The mean number of children in the family was 1.80 $(\mathrm{SD}=1.03)$. Mean birth weight was $3,537.5 \mathrm{~g}$ $(S D=823.9)$. Of all infants, $1 \%$ had a physical or 
mental disability, $4.1 \%$ had a physical disease, and 6.3\% used medication. Parental education level varied: $43.8 \%$ had a high level of education, $38.1 \%$ had a medium level of education, and $15.5 \%$ had a low level of education.

\section{Measures}

\section{Behavior problem questionnaire}

We used a combination of 55 items on a 3-point Likert scale (0 "never," 1 "sometimes," 2 "often") focusing primarily on externalizing behavior, social communication problems, and internalizing items. In selecting items, we first composed a large pool of potentially interesting items concerning children younger than 18 months by reviewing instruments for older children, namely The Infant-Toddler Social and Emotional Assessment; The Child Behavior Checklist for 1.5-5; and the Vineland Social-Emotional Early Childhood Scales [1, 7, 29, 30] and based on our clinical experience with very young children. Then a multidisciplinary panel of experts with clinical and research experience with infants and toddlers made a final selection of items based on two criteria, namely, the item had to be specific for externalizing, social communication or internalizing problem behaviors and to be usable for infants younger than 18 months. The final selection included items that covered attentional problems, hyperactivity, oppositional behavior, aggressive behavior, verbal and non-verbal aspects of social communication (such as initiating and responding) and internalizing behaviors such as problems with eating or sleeping.

\section{Data analyses}

Items were recoded in such way that a score of two represented the complete presence of an unwanted behavior or the complete absence of a wanted behavior. Common and uncommon problems were identified using the approach of Koot and Verhulst [18]. Common problems were defined as all items that scored 1 (present sometimes) or 2 (present often) for $50 \%$ or more of the sample. Uncommon problems were defined as all items that scored 1 or 2 for less than $10 \%$ of the sample.

The structure of problem behavior was examined by entering all items in a principal component analysis (PCA) with varimax rotation. The number of factors was based on the scree test [13]. Items with a minimum factor loading of $\geq 0.30$ were included $[2,4]$. To validate the findings, PCA was performed on two split half samples Pearson correlations were calcu- lated to examine the interrelationship between the factor sumscores. Finally, in order to examine possible two higher-order factors, PCA was performed requiring all items to load on two factors and Pearson correlations were calculated to examine their interrelationship.

Stability was examined parametrically by calculating Pearson correlations between scores at 14 and 19 months. Further, stability was examined nonparametrically by examining how many children with high scores (above the 75 th or 90 th percentile) on Total Problem scores and single factor scores at 14 months still had high scores at 19 months. ANOVA was performed to assess the effect of sex on the scores of each problem item and for the factor sum scores. Cohen's $d$ value is reported as an index of effect size (small, $d=0.2$; medium, $d=0.5$; or large, $d>0.8$ ) [11]. All analyses were two-tailed and a 0.05 level of significance was used. These analyses were performed using the Statistical Package for Social Sciences (SPSS for Windows, version 11.5).

\section{Results}

\section{Frequencies}

Common and uncommon problem behaviors and their frequency of occurrence are shown in Table 1. Almost all common problem behaviors were externalizing items, whereas uncommon problems were social communication and internalizing items. Seven of 13 common behavior problems and two of eight uncommon behavior problems were more common among boys than among girls.

\section{Factor structure of problem behavior}

The principal component analysis with varimax rotation with eigenvalues $>1.5$ for two equally sized split half samples resulted in two very similar solutions. The scree test suggested a seven-factor PCA solution (eigenvalue $>1.5$ ) with a percentage explained variance of $34.6 \%$ (see Appendix to this paper for details). The PCA for the 19-month-old children showed the same factors as the analysis at 14 months, with $37.7 \%$ of explained variance. Five of the 55 items had higher loadings at 19 months on other factors than at 14 months.

Pearson correlations between the factor scores (Table 2a) suggested a higher-order division into two problem domains, one reflecting total problem behaviors and one reflecting competences. Oppositional problem behavior at 14 months of age was mostly related to the factors Attention, Inhibition, 
Table 1 Common and uncommon problem behavior at 14 months

\begin{tabular}{|c|c|c|c|}
\hline & $\%$ With score 1 (sometimes) & $\%$ With score 2 (often) & $\%$ With score 1 or 2 \\
\hline \multicolumn{4}{|l|}{ Common problem behavior } \\
\hline Quickly shifts from one thing to other ${ }^{\mathrm{a}}$ & 61.9 & 26.0 & 87.9 \\
\hline Angry moods ${ }^{\mathrm{a}}$ & 63.5 & 9.6 & 73.1 \\
\hline Demands must be met & 56.8 & 14.1 & 70.9 \\
\hline Can't stand waiting, wants everything now & 51.1 & 16.2 & 67.3 \\
\hline Uses toys for fantasy play ${ }^{\mathrm{a}}$ & 35.2 & 29.8 & 65.0 \\
\hline Wants a lot of attention & 50.3 & 14.4 & 64.7 \\
\hline Accident prone & 56.4 & 6.4 & 62.8 \\
\hline Stays close to parent & 54.0 & 4.5 & 58.5 \\
\hline Easily upset & 46.3 & 7.5 & 53.8 \\
\hline Doesn't sit still during story ${ }^{\mathrm{a}}$ & 39.4 & 14.0 & 53.4 \\
\hline Won't share toys or other things ${ }^{\mathrm{a}}$ & 46.1 & 5.9 & 52.0 \\
\hline Doesn't keep trying & 46.7 & 5.1 & 51.8 \\
\hline 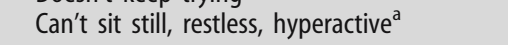 & 40.0 & 11.0 & 51.0 \\
\hline \multicolumn{4}{|l|}{ Uncommon problem behavior } \\
\hline Fails to follow with eyes & 8.0 & 1.4 & 9.4 \\
\hline Doesn't show interest in new objects & 7.1 & 0.6 & 7.7 \\
\hline Doesn't make happy noises & 6.7 & 0.8 & 7.5 \\
\hline Doesn't make noises spontaneously & 5.8 & 1.1 & 6.9 \\
\hline Has less fun than others & 4.5 & 1.5 & 6.0 \\
\hline Doesn't react at calling name ${ }^{a}$ & 5.3 & 0.6 & 5.9 \\
\hline Seems unhappy without good reason & 4.9 & 0.7 & 5.6 \\
\hline Doesn't imitate simple gestures ${ }^{\mathrm{a}}$ & 4.3 & 0.9 & 5.2 \\
\hline
\end{tabular}

Note: Common is defined as $>50 \%$ with score 1 or 2 . Uncommon is defined as $<10 \%$ with score 1 or 2 . Please note further that items covering lack of competences were recoded in such way that a score of 2 represented the complete presence of an unwanted behavior or the complete absence of a wanted behavior. This explains why all items have the same-sign factor loadings

a Significantly more boys $(P<0.001)$

and Dysregulation, with $r$ values varying between 0.37 and 0.52 and the factor Language Development was mostly related to the factors Explorative Behavior and Communicative Intent ( $r$ values of 0.41 and 0.42 , respectively). Indeed, principal component analysis confirmed the underlying structure of the higher-or- der factors when all items were forced to load on two factors and were named Total Problem Behavior (eigenvalue 6.9, explained variance 11.5\%) and Competences (eigenvalue 4.5, explained variance 7.5\%). Pearson correlation of these higher order constructs revealed a low correlation $(0.12)$.

Table 2 Pearson correlation matrix of factor sumscores of (a) 14-month-old and (b) 14- and 19-month-old

\begin{tabular}{|c|c|c|c|c|c|c|c|}
\hline Questionnaire domains & Oppositional behavior & Language development & Attention & Explorative behavior & Communicative intent & Dysregulation & Inhibition \\
\hline \multicolumn{8}{|l|}{$\begin{array}{l}14 \text { months } \\
\text { a }\end{array}$} \\
\hline Oppositional behavior & 1 & & & & & & \\
\hline Language development & -0.001 & 1 & & & & & \\
\hline Attention & $0.522^{* *}$ & $0.106^{* *}$ & 1 & & & & \\
\hline Explorative behavior & 0.005 & $0.412^{* *}$ & $0.167^{* *}$ & 1 & & & \\
\hline Communicative intent & $0.102^{* *}$ & $0.422^{* *}$ & $0.142^{* *}$ & $0.351^{* *}$ & 1 & & \\
\hline Dysregulation & $0.436^{* *}$ & 0.022 & 0.315 & $0.060^{* *}$ & $0.124^{* *}$ & 1 & \\
\hline Inhibition & $0.379^{* *}$ & $0.098^{* *}$ & $0.235^{* *}$ & $0.076^{* *}$ & $0.308^{* *}$ & $0.308^{* *}$ & 1 \\
\hline $\begin{array}{l}14 \text { months } \\
\text { b }\end{array}$ & & & 19 months & & & & \\
\hline Oppositional behavior & 0.678 & & & & & & \\
\hline Language development & 0.029 & $0.476^{* *}$ & & & & & \\
\hline Attention & $0.498^{* *}$ & $0.112^{* *}$ & $0.625^{* *}$ & & & & \\
\hline Explorative behavior & 0.089 & $0.264^{* *}$ & $0.188^{* *}$ & $0.452^{* *}$ & & & \\
\hline Communicative intent & $0.057^{* *}$ & $0.255^{* *}$ & $0.131^{* *}$ & $0.206^{* *}$ & $0.466^{* *}$ & & \\
\hline Dysregulation & $0.353^{* *}$ & $0.069^{* *}$ & $0.300^{* *}$ & $0.080^{* *}$ & $0.127^{* *}$ & $0.445^{* *}$ & \\
\hline Inhibition & $0.306^{* *}$ & $0.100^{* *}$ & $0.247^{* *}$ & $0.086^{* *}$ & $0.120^{* *}$ & $0.226^{* *}$ & 0.380 \\
\hline
\end{tabular}

Note. ${ }^{*}$ Correlation is significant at the 0.05 level (2-tailed)

**Correlation is significant at the 0.01 level (2-tailed) 
Table 3 Mean factor scores at $t_{1}$ (14 months) and $t_{2}\left(19\right.$ months) and percentage of children with scores above 90th and 75 th percentile on both 14 months $t_{1}$ and 19 months $t_{2}(N=1,803)$

\begin{tabular}{lllll}
\hline Behavioral dimension & \multicolumn{2}{l}{$\begin{array}{l}\text { Mean factor scores at } \\
t_{1} \text { and } t_{2}\end{array}$} & $\begin{array}{l}\text { \% Of children scoring }>90 \text { th } \\
\text { percentile at both } t_{1} \text { and } t_{2}\end{array}$ & $\begin{array}{l}\text { Of children scoring }>75 \text { th } \\
\text { percentile at both } t_{1} \text { and } t_{2}\end{array}$ \\
\hline Oppositional behavior & 0.37 & 0.42 & 44.8 & 60.3 \\
Language development & 0.47 & 0.44 & 31.3 & 55.8 \\
Explorative behavior & 0.42 & 0.44 & 34.2 & 50.3 \\
Attention & 0.42 & 0.42 & 45.0 & 56.7 \\
Inhibition & 0.64 & 0.65 & 29.0 & 43.7 \\
Communicative intent & 0.50 & 0.92 & 46.8 & 51.3 \\
Dysregulation & 0.73 & 0.35 & 27.5 & 51.1 \\
\hline
\end{tabular}

Note. The columns represent the percentage, of those children scoring more than 90 th/75th percentile at $t_{1}$, who were also above 90 th/75th percentile at $t_{2}$

A significant sex difference (boys had higher scores than girls) was found on several factors, namely Oppositional Behavior $(F=15.20$, df $1, P<0.000)$, Language Development $(F=108.88$, df $1, P<0.000)$, Attention $(F=22.56$, df $1, P<0.000)$, Explorative Behavior $(F=18.05$, df $1, P<0.000)$, and Communicative Intent $(F=15.76$, df $1, P<0.000)$. The effect sizes were small (Oppositional Behavior, $d=0.09$; Language Development, $d=0.26$; Attention, $d=0.11$; Communicative Intent, $d=0.10$ ). No significant sex differences were found for Dysregulation and Inhibition. At 19 months, the same sex differences were found, except for Communicative Intent.

\section{Stability over 5 months}

Pearson correlations between the factor sum scores at 14 and 19 months varied between 0.38 and 0.68 , with the highest correlation being found for the Oppositional (0.68) and the Attention factors (0.63) and the lowest for the Inhibition factor (0.38). This indicates moderate stability of the constructs of problem behavior over the 5-month period (See Table 2b).

The most stable problems were problems of Communicative Intent, Oppositional Behavior, and Attention (see Table 3). At least half of the group with scores at or above the 75th percentile range at 14month-old had high scores on problem behaviors at 19 months. With regard to the Total Problem sum scores, $75.5 \%$ of the group with scores at and above the 90th percentile of the Total Problem score at 14 months still had problem behaviors at 19 months within the75th percentile range. Also, $53.1 \%$ of the children at or above the 90th percentile still had high scores within the highest range 5 months later. On the other hand, about $88.1 \%$ of the children with scores below the 75 th percentile at 14 months remained below the 75th percentile at 19 months. However, $3.4 \%$ of the infants with the least problems on the Total Problem score at 14 months scored at or above the 90th percentile at 19 months (see Fig. 1).

\section{Discussion}

Recently, more interest has been paid to the manifestation of early problem behavior in infants and toddlers. As expected, we found externalizing behaviors to be among the most common problem behaviors in 14-month-old infants. Indeed, more than $70 \%$ of the parents reported that their children often or very often showed behavioral items such as "quickly shifts activities," "angry moods," and "demands must be met immediately." These rates are fairly comparable with the prevalence rates reported earlier for somewhat older children [18]. Although these and other common oppositional behaviors are symptoms of DSM-IV axis-I disorders such as Attention Deficit Hyperactivity Disorder, Oppositional Defiant Disorder, and Conduct Disorder at older ages, these high scores for 14-month-old infants are not necessarily psychopathological $[6,18]$. Instead, the high occurrence of parent-reported problem behaviors at this early age can best be interpreted as "relatively normal" $[18,23]$. While the symptoms and frequency of externalizing problem behaviors change with age, it is of interest to categorize these changes by their severity and to study their developmental trajectories in order to classify expected abnormal outcomes [3]. Further work should therefore focus on longitudinal studies to decide where the cut-off point is and then start to index a risk for psychopathology.

Lack of competences in social communication and internalizing problem behaviors were relatively rare, occurring in about $5-9 \%$ of the community sample. These results confirm that internalizing symptoms with possible underlying constructs of withdrawal and depression are less prevalent at this early age [4]. This is not to say that these behaviors are unimportant or should be neglected. For example, other social communication items such as "failure to follow with the eyes," "does not react to calling name," and "does not imitate simple gestures" may indicate the presence of more serious psychopathology, such as autistic spec- 
Fig. 1 Transitions (expressed as percentages of children) between 14 months and 19 months for the 90th and 75 th percentile cutoff of the total problem behavior score
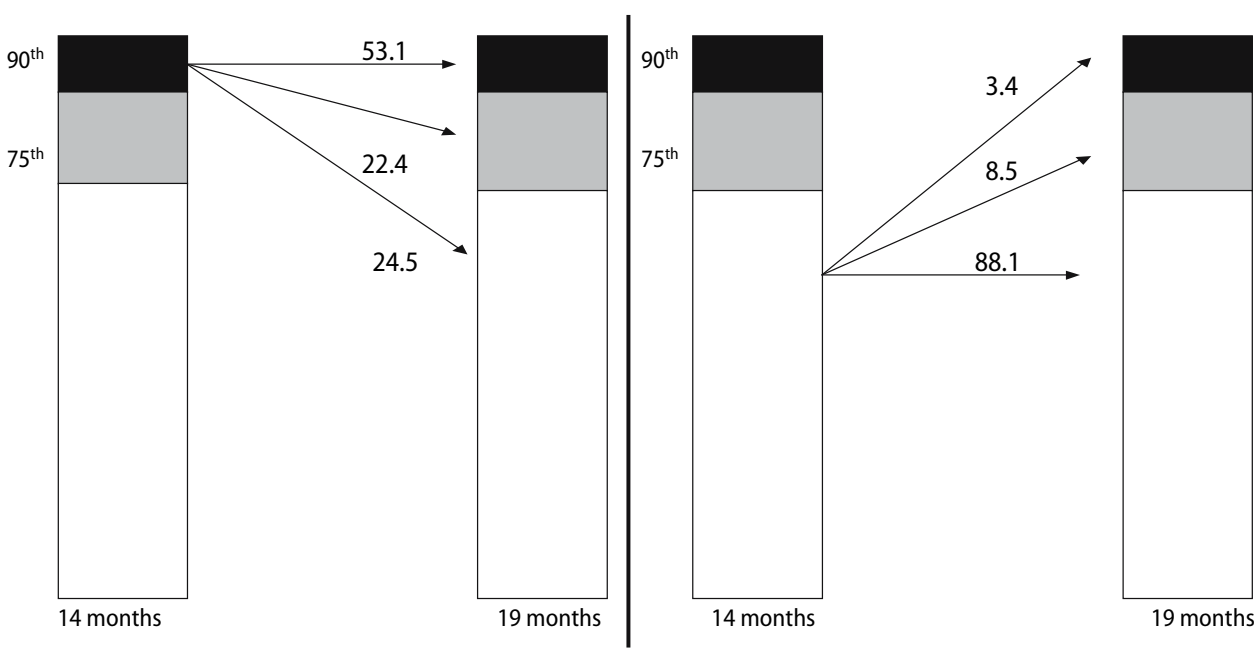

19 months to 14 months
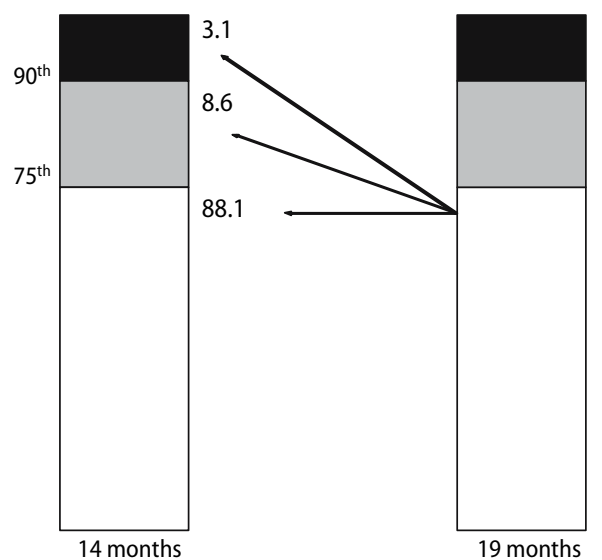
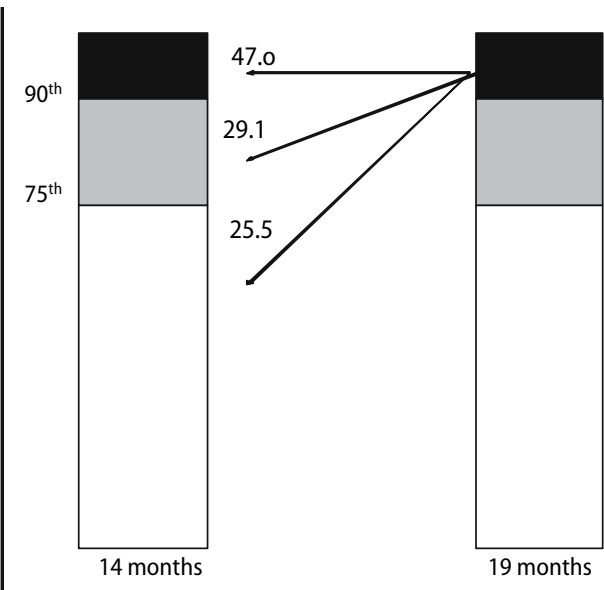

trum disorder. It would be interesting to determine whether the risk of later psychopathology is significantly higher for a combination of problem behaviors and for which combination this accounts. Also, the frequency or severity of these social communication problems is associated with a serious risk of problems later in development.

Principal component analysis of the data for the 14-month-old children indicated that seven factors could identify important behavioral dimensions. The observation that PCA revealed the same factor solutions for the original as well as for both split half samples is strong evidence for the presence of these distinct behavioral dimensions at 14 months. While the CBCL 1.5-5 [1] can detect externalizing problem behavior in 18-month-old children, our study indicates that these behaviors are present at an even younger age, 14 months. The two behavioral dimensions with the highest explained variance were dimensions describing problems in oppositional behaviors and language development. The dimension Language Development was correlated with the behavioral dimension Communicative Intent, which covers items of more nonverbal-related behaviors, and with Explorative Behavior. Ever since the work of Piaget, explorative behavior has been considered crucial for cognitive development. Explorative behavior is also an important construct in the field of attachment theory, where the infant is thought to use the attachment figure as a secure base for exploring its environment. Interestingly, the finding of a separate attentional factor refers to the emergence of attentional systems of higher-level control at 12-36 months, which contribute to the development of more goal-oriented behaviors and the ability to inhibit actions [28]. The behavioral dimension termed Inhibition consisted of items consistent with the construct of passive inhibition, namely items focusing on inhibition to novelty, separation distress, and affect-relating internalizing behaviors [16]. Eating and sleeping problems as well as more anxietyrelated problem behavior formed a Dysregulation dimension, as found in other studies [4]. Our findings suggest that even at this young age the struc- 
tures that underlie behavior problems are becoming clearer.

These behavioral dimensions are in line with dimensions described in other questionnaires. For example, our Oppositional Behavior dimension includes many items found in the Aggressive behavior factor of the CBCL 1.5-5 [1]. Items of the Communication scale of the Vineland are found in our dimension Language Development and Communicative Intent in our analysis. The latter dimension also includes some items of the Socialization scale of the Vineland [29, 30]. Next, our dimension measuring Attention consists of items from Attention dimensions of other scales (the Attention Problems of the CBCL 1.5-5 and the Attention scale of the ITSEA) [7]. Also, our dimension Explorative behavior is partly in line with ITSEA's Mastery motivation and partly with the Socialization scale of the Vineland. Furthermore, our dimension Dysregulation consists mainly of items of the Internalizing dimension of the CBCL 1.5-5. Finally, most of the items seen in our dimension Inhibition are found in the Other Problem dimension of the CBCL 1.5-5 and some are from the Internalizing and Competence domain of the ITSEA.

Inspection of the factorsumscores correlation matrix suggested two higher-order dimensions, one consisting of problems behaviors (Oppositional behavior, Attention, Dysregulation, and Inhibition) and a second one covering competences (Language Development, Explorative Behavior, and Communicative Intent). This higher order division was confirmed in a factor analysis forcing a two-factor solution. The two higher-order factors Total Problem Behavior and Competences correlated only very weakly with each other (0.12), suggesting a fairly amount of independence. Apparently a relative high level of problem behaviors is not necessarily accompanied by a relative low level of competences and vice versa. This finding is in accordance with studies using the ITSEA in older children. In these studies too, competences emerged as a separate factor from factors on problem behaviors $[4,5,9]$. For the clinical practice our result indicates that even at a very young age, a thorough evaluation of a child's functioning should include both an investigation of problem behaviors and an evaluation of competences.

With regard to sex differences, boys were reported to have significantly more problem behaviors than girls on all factors, except for dysregulation and inhibition, consistent with the finding that boys show more externalizing behaviors [18]. We found no sex differences in dysregulation and inhibition, whereas other studies report girls to be more fearful and to have more sleeping problems than boys [14, 27]. Boys were reported to have more problems in social communication behaviors, which suggests that boys acquire these competencies later than girls. This could play a role in the emergence of problem behavior among boys, whereas the early acquisition of competencies could be a protective factor for girls [4]. Contradictory reports on the presence of sex differences in problem behaviors may also be due to cultural or social factors, such as social role expectancy issues, and these may well complicate the interpretation of results.

Problems of communicative intent, oppositional problems, and attentional problems had the highest correlations and remained moderately stable over the 5 -month period between 14 and 19 months of age. The least stable were inhibition and dysregulation problems, perhaps reflecting a more temporary nature of these behaviors, as reported earlier by Briggs-Gowan and Carter [4]. At least $53 \%$ of the infants with scores within the 90th percentile of each factor sum score at 14 months still exhibited these problem behaviors at 19 months of age. These results are in accordance with other studies that have also shown substantial stability in problem behavior [21, 23]. These studies investigated children older than 19 months of age, whereas our results suggest that these problem behaviors are already moderately stable at an even younger age, emphasizing the need for early assessment. We can only speculate on the determinants of this stability, such as the child's temperament, family environment, or parental variables. It would be interesting to investigate these determinants in relation to the frequency, severity, and pervasiveness of behavior problems over a longer period of time, for example, at 14,19 , and 36 months of age, in order to gather information on how problem behavior evolves.

\section{Limitations}

One should note that we did not aim to present a new instrument to measure problem behaviors at this young age. Instead, we wanted to report on common and uncommon problem behaviors in this young age group. Although the study population was large and community based, it was not fully representative of the general population. Our sample contained more parents with a higher socioeconomic status than expected compared to the general population. Thus scores for problem behaviors might have been higher in the non-responder group. A second limitation is that we only used parent reports. Information from other sources can be of additional value to evaluate the level of problem behavior $[8,18]$. Future work should include measures of impairment of functioning and should focus on more in-depth assessments of psychopathology and level of cognitive development. Finally, it may be informative to compare a population-based sample with a clinically referred group. 


\section{Clinical implications}

This study underlines the growing need to identify problem behavior in early development. A better understanding of what is normal and abnormal in early infant-toddler development is of great value for the recognition of early psychopathology. Normative data for the prevalence and stability of behavior problems of 1- and 2-year-old children in a normal population may make it possible to provide early effective preventive intervention programs, in addition to background information for clinicians and researchers in order to develop such programs.

In summary, externalizing behaviors were the most common, and social communication the least com- mon, problems reported in a population sample of 14-month-old children. Boys were reported to show significantly more problems of externalizing behavior and competences. These behaviors were moderately stable over a 5-month period, between the ages of 14 and 19 months.

Acknowledgements Supported by the Netherlands Organisation for Health Research and Development (ZonMw) Grant 940-38-045. We are grateful to Dr. J.E.C. Sykes for her comments on the manuscript.

\section{Appendix}

\begin{tabular}{|c|c|c|c|c|}
\hline & Explained variance (\%) & Cronbach alpha & 14 months factor loadings & 19 months factor loadings \\
\hline Oppositional behavior ${ }^{\mathrm{a}}$ & 12.4 & 0.83 & & \\
\hline 1. Stubborn, sullen or irritable & & & 0.63 & 0.67 \\
\hline 2. Fussy, whining & & & 0.58 & 0.65 \\
\hline 3. Screams a lot & & & 0.57 & 0.58 \\
\hline 4. Angry Moods ${ }^{\mathrm{a}}$ & & & 0.57 & 0.66 \\
\hline 5. Sudden mood changes & & & 0.55 & 0.62 \\
\hline 6. Demands must be met & & & 0.52 & 0.67 \\
\hline 7. Is extremely loud ${ }^{\mathrm{a}}$ & & & 0.53 & 0.51 \\
\hline 8. Easily upset & & & 0.52 & 0.59 \\
\hline 9. Uncooperative ${ }^{a}$ & & & 0.53 & 0.55 \\
\hline 10. Can't stand waiting; wants everything now & & & 0.49 & 0.62 \\
\hline 11. Hurts animals or people ${ }^{\mathrm{a}}$ & & & 0.51 & 0.54 \\
\hline 12. Bites, kicks or hits others ${ }^{a}$ & & & 0.50 & 0.58 \\
\hline 13. Cries a lot & & & 0.43 & 0.55 \\
\hline 14. Won't share toys or other things ${ }^{a}$ & & & 0.37 & 0.44 \\
\hline 15. Accident Prone ${ }^{a}$ & & & 0.32 & 0.38 \\
\hline Language development ${ }^{\mathrm{a}}$ & 7.7 & 0.68 & & \\
\hline 16. Uses correct gestures to express ${ }^{a}$ & & & 0.69 & 0.68 \\
\hline 17. Understands at least 10 words $^{\mathrm{a}}$ & & & 0.66 & 0.66 \\
\hline 18. Points at things to show ${ }^{\mathrm{a}}$ & & & 0.62 & 0.62 \\
\hline 19. Uses common names like "mummy/daddy"d & & & 0.55 & 0.46 \\
\hline 20. Imitates sounds of parent ${ }^{\mathrm{a}}$ & & & 0.42 & 0.46 \\
\hline 21. Reacts to being called by name ${ }^{a}$ & & & 0.34 & 0.36 \\
\hline Attention ${ }^{\mathrm{a}}$ & 3.7 & 0.64 & & \\
\hline 22. Can't sit still; restless or hyperactive $e^{a}$ & & & 0.56 & 0.61 \\
\hline 23. Quickly shifts from one thing to another ${ }^{a}$ & & & 0.54 & 0.60 \\
\hline 24. Can't concentrate or pay attention for long & & & 0.53 & 0.64 \\
\hline 25. Plays with toys for longer than $5 \mathrm{~min}$ & & & 0.52 & 0.60 \\
\hline 26. Wants a lot of attention & & & 0.45 & 0.44 \\
\hline 27. Sits still for 5 min during reading ${ }^{a}$ & & & 0.38 & 0.47 \\
\hline Explorative behavior $^{\mathrm{a}}$ & 3.1 & 0.63 & & \\
\hline 28. Enjoys learning new things ${ }^{a}$ & & & 0.56 & 0.49 \\
\hline 29. Keeps trying & & & 0.55 & 0.53 \\
\hline 30. Wants to do things for self ${ }^{a}$ & & & 0.58 & 0.50 \\
\hline 31. Pays attention when being explained & & & 0.49 & 0.44 \\
\hline 32. Uses toys for fantasy play & & & 0.46 & 0.41 \\
\hline 33. Shows interest in new objects & & & 0.39 & 0.51 \\
\hline 34. When finished, he/she finds other things to play with & & & 0.36 & 0.42 \\
\hline 35. Shows interest in familiar objects & & & 0.35 & 0.51 \\
\hline
\end{tabular}




\begin{tabular}{|c|c|c|c|c|}
\hline & Explained variance (\%) & Cronbach alpha & 14 months factor loadings & 19 months factor loadings \\
\hline Communicative intent $^{\mathrm{a}}$ & 2.7 & 0.53 & & \\
\hline 36. Babbles, makes noises spontaneously ${ }^{\mathrm{a}}$ & & & 0.59 & 0.67 \\
\hline 37. Makes sounds of joy & & & 0.54 & 0.52 \\
\hline 38. Follows with eyes when someone moves & & & 0.46 & 0.56 \\
\hline 39. Stops fussing when being spoken to & & & 0.32 & 0.28 \\
\hline 40. Clings to parent & & & 0.34 & 0.37 \\
\hline 41. Reaches when he/she wants to be held & & & 0.40 & 0.52 \\
\hline 42. Imitates simple gestures such as applauding ${ }^{a}$ & & & 0.44 & 0.55 \\
\hline Dysregulation & 2.6 & 0.61 & & \\
\hline 43. Can't sleep alone & & & 0.71 & 0.60 \\
\hline 44. Trouble getting to sleep & & & 0.65 & 0.65 \\
\hline 45. Doesn't eat well ${ }^{\mathrm{b}}$ & & & 0.35 & 0.15 \\
\hline 46. Has less fun than other children & & & 0.45 & 0.31 \\
\hline 47. Refuses to play active games & & & 0.35 & 0.19 \\
\hline 48. Seems unhappy without good reason & & & 0.43 & 0.36 \\
\hline Inhibition & 2.5 & 0.45 & & \\
\hline 49. Quiet or still in new situations ${ }^{b}$ & & & 0.45 & 0.52 \\
\hline 50. Is afraid of certain animals, things or places ${ }^{b}$ & & & 0.38 & 0.37 \\
\hline 51. Stays close to parent & & & 0.42 & 0.50 \\
\hline 52. When cries, he/she stays in place, waits for parent ${ }^{a}$ & & & 0.44 & 0.44 \\
\hline 53. Is easily scared & & & 0.45 & 0.52 \\
\hline 54. Wants help constantly & & & 0.40 & 0.42 \\
\hline 55. Stays still while being changed or washed ${ }^{a}$ & & & 0.37 & 0.24 \\
\hline
\end{tabular}

Note. ${ }^{\text {a }}$ Means significantly more boys $(P<0.001)$

${ }^{\mathrm{b}}$ Means significantly more girls $(P<0.001)$

\section{References}

1. Achenbach TM, Rescorla LA (2000) Manual for ASEBA preschool forms \& profiles. University of Vermont, Research Center for Children, Youth, \& Families, Burlington, VT

2. Achenbach TM, Edelbrock C, Howell CT (1987) Empirically based assessment of the behavioral/emotional problems of 2- and 3-year-old children. J Abnorm Child Psychol 15:629-650

3. Bongers IL, Koot HM, van der Ende J, Verhulst FC (2004) Developmental trajectories of externalizing behaviors in childhood and adolescence. Child Dev 75:1523-1537

4. Briggs-Gowan MJ, Carter AS (1998) Preliminary acceptability and psychometrics of the infant-toddler social and emotional assessment (ITSEA): a new adult-report questionnaire. Infant Mental Health J 19:422-445

5. Briggs-Gowan MJ, Carter AS, Skuban EM, Horwitz SM (2001) Prevalence of social-emotional and behavioral problems in a community sample of 1- and 2-year-old children. J Am Acad Child Adolesc Psychiatr 40:811-819

6. Campbell SB, Ewing LJ (1990) Followup of hard-to-manage preschoolers: adjustment at age 9 and predictors of continuing symptoms. J Child Psychol Psychiatr 31:871-889
7. Carter AS, Briggs-Gowan MJ (2000) Infant toddler social and emotional assessment (ITSEA) manual. Conneticut Early Development Project, New Haven CT

8. Carter AS, Briggs-Gowan MJ, Davis NO (2004) Assessment of young children's social-emotional development and psychopathology: recent advances and recommendations for practice. J Child Psychol Psychiatr 45:109-134

9. Carter AS, Briggs-Gowan MJ, Jones SM, Little TD (2003) The infant-toddler social and emotional assessment (ITSEA): factor structure, reliability, and validity. J Abnorm Child Psychol 31:495-514

10. Caspi A, Moffitt TE, Newman DL, Silva PA (1996) Behavioral observations at age 3 years predict adult psychiatric disorders. Longitudinal evidence from a birth cohort. Arch Gen Psychiatr 53:1033-1039

11. Cohen J (1988) Statistical power analysis for the behavioral sciences, 2nd edn. Lawrence Earlbaum Associates, Hillsdale, N.J

12. Cornely P, Bromet E (1986) Prevalence of behavior problems in 3-year-old children living near three mile island a comparative-analysis. J Child Psychol Psychiatr Allied Disciplines 27:489-498
13. De Heus P, Van der Leeden R, Gazendam B (1995) Techniques of applied data-analyses for non-experimental research in social sciences (Toegepaste Data-analyse technieken voor niet-experimenteel onderzoek in de sociale wetenschappen). uitgeverij Lemma, Utrecht

14. Earls F (1980) Prevalence of behavior problems in 3-year-old children - a cross-national replication. Arch Gen Psychiatr 37:1153-1157

15. Jenkins S, Bax M, Hart H (1980) Behavior problems in pre-school children. J Child Psychol Psychiatr 21:5-17

16. Kagan J, Snidman N, Arcus D, Reznick JS (1998) Galen's prophecy: temperament in human nature. Boulder, Colorado, Westview Press

17. Keenan K, Shaw D, Delliquadri E, Giovannelli J, Walsh B (1998) Evidence for the continuity of early problem behaviors: application of a developmental model. J Abnorm Child Psychol 26:441-452

18. Koot HM, Verhulst FC (1991) Prevalence of problem behavior in Dutch children aged 2-3. Acta Psychiatr Scand Suppl 367:1-37 
19. Koot HM, Van den Oord EJCG, Verhulst FC, Boomsma DI (1997) Behavioral and emotional problems in young preschoolers: cross-cultural testing of the validity of the child behavior checklist/2-3. J Abnorm Child Psychol 25:183-196

20. Larson CP, Pless IB, Miettinen O (1988) Preschool behavior disorders - their prevalence in relation to determinants. J Pediatr 113:278-285

21. Lavigne JV, Arend R, Rosenbaum D, Binns HJ, Christoffel KK, Gibbons RD (1998) Psychiatric disorders with onset in the preschool years: I. Stability of diagnoses. J Am Acad Child Adolesc Psychiatr 37:1246-1254

22. Lavigne JV, Gibbons RD, Christoffel KK, Arend R, Rosenbaum D, Binns H, Dawson N, Sobel H, Isaacs C (1996) Prevalence rates and correlates of psychiatric disorders among preschool children. J Am Acad Child Adolesc Psychiatr 35:204-214
23. Mathiesen KS, Sanson A (2000) Dimensions of early childhood behavior problems: Stability and predictors of change from 18 to 30 months. J Abnorm Child Psychol 28:15-31

24. Newth SJ, Corbett J (1993) Behaviour and emotional problems in three-yearold children of Asian parentage. J Child Psychol Psychiatr 34:333-352

25. Office for Statistics (Centraal Bureau voor Statistiek) (2003) CBS, Voorburg

26. Richman N (1982) The 1st year of life Shaffer D, Dunn J. Personal Individual Diff 3:471

27. Richman N, Stevenson JE, Graham PJ (1975) Prevalence of behavior problems in 3-year-old children - epidemiological study in a London Borough. J Child Psychol Psychiatr Allied Disciplines 16:277-287

28. Ruff HA, Rothbart MK (1996) Attention in early development: themes and variations. Oxford University Press Inc., New York

29. Sparrow SS, Balla DA, Chicchetti DV (1984) Vineland adaptive behavior scales: manual. American Guidance Service, Circles Pines, MN
30. Sparrow SS, Balla DA, Cicchetti DV (1997) Vineland social-emotional early childhood scales: manual. American Guidance Service, Circles Pines, MN

31. Stallard P (1993) The behavior of 3year-old children - prevalence and parental perception of problem behavior - a research note. J Child Psychol Psychiatr Allied Disciplines 34:413-421

32. Thompson MJJ, Stevenson J, SonugaBarke E, Nott P, Bhatti Z, Price A, Hudswell M (1996) Mental health of preschool children and their mothers in a mixed urban rural population .1. Prevalence and ecological factors. Brit J Psychiatr 168:16-20

33. Zeanah $\mathrm{CH}$, Boris NW, Larrieu JA (1997) Infant development and developmental risk: a review of the past 10 years. J Am Acad Child Adolesc Psychiatr 36:165-178

34. Zeanah $\mathrm{CH}$, Larrieu JA, Heller SS, Valliere J, Hinshaw-Fuselier S, Aoki Y, Drilling M (2001) Evaluation of a preventive intervention for maltreated infants and toddlers in foster care. J Am Acad Child Adolesc Psychiatr 40:214221 